\title{
Prevalence and seasonal variation of human intestinal parasites in patients attending hospital with abdominal symptoms in northern Jordan
}

A.S. Jaran ${ }^{1}$

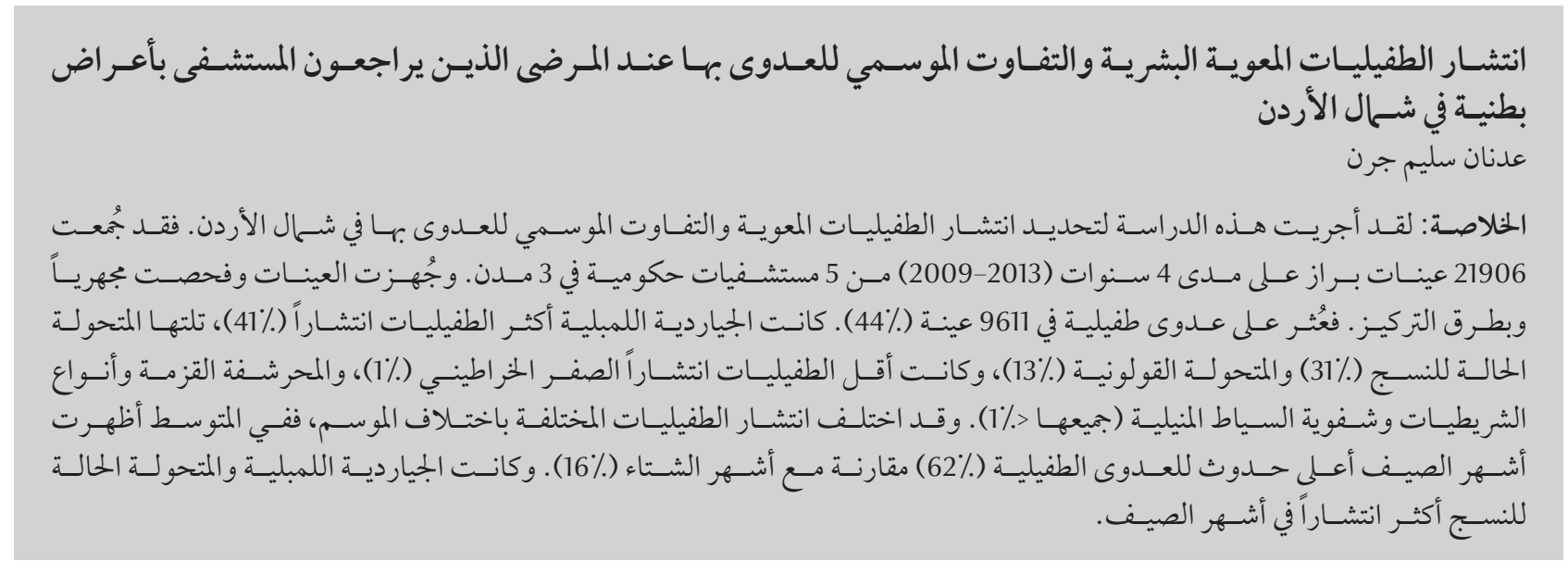

ABSTRACT This study was carried out to determine the prevalence of intestinal parasites and their seasonal variation in northern Jordan. A total of 21906 stool samples were collected over a period of 4 years (20092013) from 5 government hospitals in 3 cities. Samples were processed and examined microscopically and by concentration methods. Parasitic infection was found in 9611 samples (44\%). Giardia lamblia was the most prevalent parasite (41\%) followed by Entamoeba histolytica (31\%) and Ent. coli (13\%); the least prevalent parasites were Ascaris lumbricoides (1\%), Hymenolepis nana, Taenia sp., and Chilomastix mesnili (all < 1\%). The prevalence of different parasites varied according to season, on average the summer months showed the highest incidence of parasitic infection (62\%) compared with the winter months (16\%). Giardia lamblia and Ent. histolytica were most prevalent in the summer months.

Prévalence et variations saisonnières de parasites intestinaux humains chez des patients consultant en hôpital pour des symptômes abdominaux dans le nord de la Jordanie

RÉSUMÉ La présente étude a été menée afin de déterminer la prévalence de parasites intestinaux ainsi que leur variation saisonnière dans le nord de la Jordanie. Un total de 21906 échantillons de selles ont été collectés sur une période de 4 ans (2009-2013) dans cinq hôpitaux gouvernementaux de trois villes. Les échantillons ont été traités et examinés à la microscopie et à l'aide de méthodes de concentration. Une infection parasitaire a été trouvée dans 9611 échantillons (44\%). Giardia lamblia était le parasite avec la prévalence la plus élevée (41 \%), suivi par Entamoeba histolytica (31 \%) et Entamoeba coli (13\%). Les parasites ayant la plus faible prévalence étaient Ascaris lumbricoides (1\%), Hymenolepis nana, Taenia sp., et Chilomastix mesnili (tous < 1 \%). La prévalence des différents parasites variait en fonction de la saison : en moyenne, les mois d'été affichaient la plus haute incidence d'infections parasitaires (62\%) comparés aux mois d’hiver (16\%). Giardia lamblia et Ent. histolytica étaient les plus prévalents au cours des mois d'été. 


\section{Introduction}

Intestinal parasitic diseases are among the most common infections worldwide and more prevalent in the poorest communities of the developing world $(1-4)$. These infections are regarded as a serious public health problem as they can cause iron-deficiencyanaemia $(5,6)$, malnutrition (7), growth retardation in children and other physical and mental health disorders $(8,9)$. Most clinicians and health workers do not consider parasitic infections as life threating, and most of the time they go unnoticed or are misdiagnosed (10). Consequently, not much attention is given to treating these diseases.

Very few studies have been carried out in Jordan dealing with parasitic infections, and those that have been done only discussed specific cases or incidents involving diarrhoea. Studies that dealt with parasites either concentrated on infants and children or adults in specific carriers such as food handlers (11-14). The current study may be the first comprehensive study to determine the prevalence of intestinal parasites over a long period in a large sample of Jordanians.

The aim of this study was to determine the prevalence of human intestinal parasites and their seasonal variation in the north of Jordan, where approximately a third of the Jordanian population live. Patients attending major hospitals in Irbid, Jerash and Ajlun were studied.

\section{Methods}

\section{Study design}

The study was conducted over a period of 4 years (2009-2013) with the cooperation of major hospitals in 3 cites. The fieldwork involved the collection of stool samples from all patients attending these hospitals complaining of abdominal pain or stomach complaints.

The study was carried out at hospitals in 3 main cities in northern Jordan, Irbid, Jerash and Ajlun, 3 hospitals in Irbid (Princess Badea, Princess Basma and Princess Rahma Children's Hospital), 1 hospital in Jerash and 1 hospital in Ajlun. These are all governmental hospitals and serve a large population of Jordanians, 1626300 in total (including 1112300 in Irbid, 187500 in Jerash and 143700 in Ajlun) according to the latest census in 2015. North Jordan is home to people living in diverse socioeconomic conditions, from refugee camps (lower socioeconomic conditions) to modern cities with a high standard of living.

The climate of north Jordan varies from very hot and dry during the summer months (June-September) to cold and wet during the winter months (November-February). Stool samples were obtained from patients attending the hospitals with stomach or abdominal complaints (21 906 samples in total). The patients were divided into groups according to age, adults ( $>15$ years, samples obtained from Princess Badea, Princess Basma, Jerash and Ajlun hospitals) and children ( $0-15$ years, samples obtained from Princess Rahma Children's Hospital, Jerash and Ajlun hospitals).

\section{Sample collection and analysis}

Stool samples were collected in clean plastic containers and transferred to the microbiology laboratory at $\mathrm{Al}$ alBayt University, where the experimental work was done. Patients were asked to provide fresh faecal samples. Stool specimens were examined for intestinal parasites using the standard routine methods used by hospitals and microbiological laboratories for diagnosing parasites (15). A direct saline smear preparation was made and examined by light microscopy. For differential diagnosis of protozoa cysts, another preparation was made using Lugol's solution. Samples which did not show any intestinal parasites by direct smear were examined using the zinc sulphate flotation concentration technique. For the detection of Enterobius vermicularis cellophane tape preparation were used and examined either directly or by placing 1-2 drops of xylene between tape and slide. Samples that were not examined on the same day were kept at $4^{\circ} \mathrm{C}$.

\section{Statistical analysis}

The chi-square test was used for comparing data. The level of significance was set at $P<0.05$.

\begin{tabular}{|c|c|c|c|c|c|c|c|c|c|}
\hline \multirow[t]{3}{*}{ City } & \multicolumn{4}{|c|}{$\operatorname{Sex}(P=0.673)$} & \multicolumn{5}{|c|}{ Age (years) $(P=0.04)$} \\
\hline & \multicolumn{2}{|c|}{ Male } & \multicolumn{2}{|c|}{ Female } & \multicolumn{2}{|c|}{ 0-15 } & \multicolumn{2}{|c|}{$>15$} & \multirow[t]{2}{*}{ Total } \\
\hline & No. & $\%$ & No. & $\%$ & No. & $\%$ & No. & $\%$ & \\
\hline Irbid & 1614 & 51 & 1551 & 49 & 1070 & 33.8 & 2095 & 66.2 & 3165 \\
\hline Jerash & 2391 & 48.1 & 2576 & 51.9 & 902 & 18.8 & 3890 & 81.2 & 4967 \\
\hline Ajlun & 724 & 49 & 755 & 51 & 515 & 34.8 & 964 & 65.2 & 1479 \\
\hline Total & 4729 & 50.3 & 4882 & 49.7 & 2487 & 26.4 & 6949 & 73.6 & 9611 \\
\hline
\end{tabular}




\begin{tabular}{lcccc}
\hline Table 2 Distribution of intestinal parasite species in three main cities in northern Jordan, 2009-2013 & Ajlun* & Total \\
Parasite & Irbid & Jerash* & 314 & 3953 \\
Giardia lamblia & 1234 & 2405 & 384 & 3021 \\
Entamoeba histolytica & 1312 & 1325 & 272 & 1254 \\
Entamoeba coli & 420 & 562 & 227 & 634 \\
Enterobius vermicularis & 115 & 292 & 153 & 533 \\
Trichomonas hominis (vaginalis) & 140 & 240 & 37 & 82 \\
Hymenolepis nana & 17 & 27 & 9 & 48 \\
Taenia sp. & 12 & 42 & 18 & 84 \\
Ascaris lumbricoides & 24 & - & - & 2 \\
Chilomastix mesnili & 2 & 42 & \\
\hline
\end{tabular}

${ }^{*} P<0.05$.

\section{Results}

A total of 21906 stool samples were collected over the study period of 4 years, of which 9611 samples tested positive for parasitic infection (44\%). The sex and age distribution of patients that showed positive results are shown in Table 1. Sex of the patient did not show any statistical significance in relation to the presence of intestinal parasites, $(P=0.673)$; however, the relationship with age was statistically significant $(P$ $=0.043$ ).

Patients attending hospital in Irbid and Jerash had significantly higher prevalence of parasitic infection than those from Ajlun $(P<0.05)$ (Table 2).

Giardia lamblia was the most prevalent parasite (41\%), followed by Ent. histolytica (31\%) and Ent. coli (Table 3).

The prevalence of different parasites varied in different seasons: on average the summer months (June-September) showed the highest incidence of parasitic infection (62\%), with a peak in September, compared with the winter months (November-February) (16\%), with a peak in January; this was statistically significant $(P<0.05)$. Giardia lamblia and Ent. histolytica were the most prevalent in the summer months ( $\mathrm{Ta}$ ble 3).

\section{Discussion}

Parasitic infections occur most commonly in poor areas with low standards of hygiene. In Jordan, parasitic infection has been found to be most prevalent in rural areas and refugee camps (16). The current study shows that intestinal parasitic infections are common in urban areas of Jordan (44\%), with Giardia lamblia the most prevalent parasite (41\%), followed by Ent. histolytica (31\%). This is in agreement with a 2007 study by

\begin{tabular}{|c|c|c|c|c|c|c|c|c|c|c|c|}
\hline \multirow[t]{2}{*}{ Month } & \multirow{2}{*}{$\begin{array}{c}\text { No.of } \\
\text { specimens } \\
\text { examined }\end{array}$} & \multirow{2}{*}{$\begin{array}{l}\text { No. (\%) } \\
\text { infected }\end{array}$} & \multicolumn{9}{|c|}{ No. (\%) of parasite species identified in infected stool samples } \\
\hline & & & GL & EH & EC & TH & EV & Ts & HN & $\mathrm{CM}$ & AL \\
\hline January & 1056 & $103(10)$ & $25(24)$ & $34(33)$ & $32(31)$ & $12(12)$ & - & - & - & - & - \\
\hline February & 2023 & $238(12)$ & $95(40)$ & $77(33)$ & $63(27)$ & - & - & - & 3 & - & - \\
\hline March & 1875 & $598(32)$ & 236 (39) & $214(36)$ & 69 (12) & $25(4)$ & $32(5)$ & $5(1)$ & $8(1.4)$ & - & $9(1.6)$ \\
\hline April & 1798 & $999(56)$ & $482(48)$ & 238 (24) & 216 (22) & - & $30(3)$ & $7(<1)$ & $11(1)$ & - & $15(1.5)$ \\
\hline May & 2594 & $1194(46)$ & $540(45)$ & 404 (33) & $108(9)$ & - & $112(9)$ & $8(<1)$ & $9(<1)$ & - & $13(1)$ \\
\hline June & 2592 & $1412(54)$ & $632(45)$ & 414 (29) & $127(9)$ & $105(7)$ & $105(7)$ & $6(<1)$ & $12(<1)$ & - & $11(<1)$ \\
\hline July & 2620 & 1397 (55) & $591(42)$ & $526(38)$ & $94(7)$ & $75(5)$ & $81(6)$ & $8(<1)$ & $12(<1)$ & - & $10(<1)$ \\
\hline August & 2356 & 1299 (55) & $602(46)$ & $463(36)$ & $117(9)$ & $43(3)$ & $38(3)$ & $7(<1)$ & 13(1) & $2(<1)$ & $14(1)$ \\
\hline September & 1234 & $1032(84)$ & $315(30)$ & 267 (26) & $208(20)$ & $126(12)$ & $96(9)$ & - & $8(<1)$ & - & 12(1) \\
\hline October & 1345 & $836(62)$ & 235 (28) & 203(24) & 107 (13) & 140 (17) & $138(16)$ & $7(<1)$ & $6(<1)$ & - & - \\
\hline November & 1379 & $294(21)$ & 115 (39) & $103(35)$ & $76(26)$ & - & - & - & - & - & - \\
\hline December & 1034 & 209 (20) & $85(41)$ & $78(37)$ & 37 (18) & $7(3)$ & $2(1)$ & - & - & - & - \\
\hline Total & 21906 & 9611(44) & 3953 (41) & 3021 (31) & 1254 (13) & $533(6)$ & $634(7)$ & $48(<1)$ & $82(<1)$ & $2(<1)$ & $84(1)$ \\
\hline
\end{tabular}

$G L=$ Giardia lamblia $E H=$ Entamoeba histolytica $; E C=$ Entamoeba coli; $T H=$ Trichomonas hominis (vaginalis); $E V=$ Enterobius vermicularis; $T S=$ Taenia sp.; $H N=$ Hymenolepis nana; $C M=$ Chilomastix mesnili; $A L=$ Ascaris lumbricoides. 
Chazal and Adi (14), who reported that Ent. histolytica was the most frequent intestinal parasites followed by Giardia lamblia. They also reported low incidence of Ascaris lumbricoides, Enterobius vermicularis, Strongyloides stercoralis and Trichomonas hominis. They also noted higher incidence of infections with Ent. histolytica in spring and summer months compared with autumn and winter, which is also in agreement with the findings of the current study. In another study done in Jordan in 2006, Giardia lamblia (61.5\%) and Ent. histolytica (19.6\%) were the most prevalent intestinal parasites in the Amman area (central Jordan) (17). In Saudi Arabia a 2011 study showed that the majority of patients were infected by Ent. histolytica (4.7\%) and Giardia lamblia (1.3\%) (18); Ancylostoma duodenale exhibited the lowest prevalence. A study carried out at Al-Najah University in the West Bank in 2011 also found that the most prevalent intestinal parasite was Ent. histolytica (9.7\%) followed by Giardia lamblia (4.1\%) (19). The difference between our results and theirs may be a reflection of the difference in sample size and duration of the study. Comparing our results to other studies in Turkey, which has colder winters and milder summers, the most prevalent intestinal parasite was Enterobius vermicularis (13.8\%) followed by Giardia intestinalis (6.1\%) and Ent. coli (4.6\%) $(20,21)$. In general Giardia lamblia and Ent. histolytica were found to be the most prevalent intestinal parasites compared with helminth infestation.

Some clinicians and public health workers do not consider intestinal parasites to be an important problem so infected people are commonly not treated or improperly treated, especially for worm infections (21). Our findings should change the view of most clinician in Jordan: intestinal parasitic infections are important issues facing the population and more attention should be paid to the problem. Treating these infections is of the utmost importance along with prevention by giving advice to patients on hygiene and general cleanliness. Attention should be focused on public health education.

Our research had shed light on the prevalence of parasitic infection in northern Jordan; for a better understanding of the problem in Jordan as a whole, and for more reliable data to consolidate the results, a further survey is needed, which should involve most of the hospitals and clinics in the country.

\section{Acknowledgements}

We are grateful to the staff of all primary health care centres and all patients included in this study for their support and assistance.

\section{Funding: None.}

Conflict of interests: None declared.

\section{References}

1. Adedayo O, Nasiiro R. Intestinal parasitoses. J Natl Med Assoc. 2004 Jan;96(1):93-6. PMID:14746358

2. Hotez P. Hookworm and poverty. Ann N Y Acad Sci. 2008;1136:38-44. PMID:17954674

3. Farook MU, Sudharmini S, Remadevi S, Vijayakumar K. Intestinal helminthic infestations among tribal populations of Kottoor and Achankovil areas in Kerala (India). J Commun Dis. 2002 Sep;34(3):171-8. PMID:14703051

4. The Millennium Development Goals and deworming. Report of the third global meeting of the partners for parasite control: deworming for health and development, 29-30 November 2004. Geneva: World Health Organization, 2005:25-6.

5. Brito LL, Barreto ML, Silva Rde C, Assis AM, Reis MG, Parraga I, et al. Fatores de risco para anemia por deficiência de ferro em crianças e adolescentes parasitados por helmintos intestinais. [Risk factors for iron-deficiency anemia in children and adolescents with intestinal helminthic infections]. Rev Panam Salud Publica. 2003 Dec;14(6):422-31. PMID:14769159

6. Rice JE, Skull SA, Pearce C, Mulholland N, Davie G, Carapetis JR. Screening for intestinal parasites in recently arrived children from East Africa. J Paediatr Child Health. 2003 Aug;39(6):456-9. PMID:12919501

7. Intestinal protozoan and helminthic infection. Geneva: World Health Organization; 1981 (Technical Report Series No. 666).

8. Easton A. Intestinal worms impair child health in the Philippines. BMJ. 1999 Jan 23;318(7178):214. PMID:9915719

9. Oberhelman RA, Guerrero ES, Fernandez ML, Silio M, Mercado D, Comiskey N, et al. Correlations between intestinal parasitosis, physical growth, and psychomotor development among infants and children from rural Nicaragua. Am J Trop Med Hyg. 1998 Apr;58(4):470-5. PMID:9574794

10. Hotez PJ, Molyneux DH, Fenwick A, Kumaresan J, Sachs SE, Sachs JD, et al. Control of neglected tropical diseases. N Engl J Med. 2007 Sep 6;357(10):1018-27. PMID:17804846

11. Abdel-Dayem M, Al Zou'bi R, Hani RB, Amr ZS. Microbiological and parasitological investigation among food handlers in hotels in the Dead Sea area, Jordan. J Microbiol Immunol Infect. 2014 Oct; 47(5):377-80. PMID:23933293

12. al-Lahham AB, Abu-Saud M, Shehabi AA. Prevalence of Salmonella, Shigella and intestinal parasites in food handlers in Irbid, Jordan. J Diarrhoeal Dis Res. 1990 Dec;8(4):160-2. PMID:2081882

13. Shakkoury WA, Wandy EA. Prevalence of Giardia lamblia infection in Amman, Jordan. Pak J Med Sci. 2005;21(2):199-201.

14. Chazal AM, Adi HK. The prevalence of intestinal parasites in Amman, Jordan. Bull Pharm Sci Assiut University. 2007;30(2):235-9.

15. McHardy IH, Wu M, Shimizu-Cohen R, Couturier MR, Humphries RM. Detection of intestinal protozoa in the clinical laboratory. J Clin Microbiol. 2014 Mar;52(3):712-20. PMID:24197877

16. Directorate for disease prevention \& control study of intestinal parasites in Jordan. Amman: Ministry of Health and World Health Organization; 1996:3.

17. Al-Momani. T, Jaber, M, Abdallat. H, Abbadi M. Frequency of intestinal parasites at Princess Aysha Medical Complex, Marka, Jordan. J R Med Serv. 2006;13(1):70-73. 
18. Zaglool DAM, Khodari YAW, Gazzaz ZJ, Dhafar KO, Shaker HAS, Farooq MU. Prevalence of intestinal parasites among patients of Al-Noor Specialist Hospital, Makkah, Saudi Arabia. Oman Med J. 2011 May;26(3):182-5. PMID:22043412

19. Hussein AS. Prevalence of intestinal parasites among schoo children in northern districts of West Bank-Palestine. Trop Med Int Health. 2011 Feb;16(2):240-4. PMID:21073639
20. Okyay P, Ertug S, Gultekin B, Onen O, Beser E. Intestinal parasites prevalence and related factors in school children, a western city sample-Turkey. BMC Public Health. 2004 Dec;4:64. PMID:15615592

21. Aksoy U, Akisü C, Bayram-Delibaş S, Ozkoç S, Sahin S, Usluca $\mathrm{S}$. Demographic status and prevalence of intestinal parasitic infections in schoolchildren in Izmir, Turkey. Turk J Pediatr. 2007 Jul-Sep;49(3):278-82. PMID:17990581 